УДК 786.2+78.071

\title{
E. Мирзоян
}

\section{ОБРАЗ МЕДЕИ В ОДНОИМЕННОЙ ОПЕРЕ Л. КЕРУБИНИ И ЕЕ ИСПОЛНИТЕЛЬСКИЕ ВЕРСИИ}

\begin{abstract}
В статье рассмотрен выразительный потенциал стиля оперы Л. Керубини «Медея» и его соответствие требованиям революционного классицизма. Дается характеристика мифологической подоплеки главного образа оперы - Медеи - на примере исполнительского искусства М. Каллас. В ходе исследования доказана оригинальность теоретической идеи протоэкспрессионистского смысла образа Медеи и оперы Л. Керубини в иелом в противовес проромантическим установкам слышания «героического и высокого».
\end{abstract}

Ключевые слова: протоэкспрессионизм, миф, образ, исполнительское искусство, М. Каллас.

Актуальность темы исследования определена значимостью данной оперы в репертуаре оперных певиц второй половины XX - начала XXI веков. С подачи великой М. Каллас, для которой данная героиня стала alter ego в ее жизненной реализации, указанная партия, причем в оригинальной версии оперы с разговорными диалогами, составила одну из центральных точек приложения всех творческих сил. Мифологическая подоснова данного образа составила привлекательный момент современных сценических устремлений, отмеченных депсихологизацией и деперсонализацией действующих лиц на сцене - как это было заложено еще в театре-модерн Б. Брехта 1920-х годов и сформировано в сценических действах И. Стравинского и К. Орфа. Стилевая симультанность творения Л. Керубини, создавшего указанное оперное произведение на грани столетий $(1797$, см. материалы $[5 ; 8])$ и тем определившегося в стилевой многосоставности, обнаружившей интенсивный поисковый показатель на сломе эпох, стала интересной «точкой отталкивания» для режисерски-исполнительских открытий второй половины XX века.

Цель данной статьи - обрисовать выразительный потенциал стиля «Медеи» Л. Керубини в его направленности к проэкспрессионистским установкам искусства середины XX века, определившим специальную миссию произведения и роли главной героини в творческой судьбе М. Каллас.

Конкретные задания: 1) систематизация материалов по существу вписанности в «дух времени» названной оперы Л. Керубини, 2) ана-

(C) Мирзоян Е., 2016 
лиз партии Медеи в ее направленности на проэкспрессионистские установки музыкального театра второй половины ХХ века.

Методологический базис - интонационная концепция музыки, завещанная Б. Асафьевым [1] и его последователями в России [7; 8], в Украине [4], в Польше [6], в основу которой заложены культурологический подход, стилево-компаративный и герменевтический методы.

Объект исследования - творчество Л. Керубини в контексте стилевых предпочтений середины XX века, предмет - образ Медеи одноименной оперы названного композитора в русле репертуарных выборов оперных певиц второй половины XX столетия. Научная новизна - оригинальность теоретической идеи протоэкспрессионистского смысла образа Медеи и оперы Л. Керубини в целом, в противовес проромантическим установкам слышания «героического и высокого» [8, с. 181] в указанном персонаже.

Судьба оперы «Медея» Л. Керубини весьма непроста в истории театра, особенности которой отражены в характеристике Р. А. Цондергельда: «Из многих опер Л. Керубини «Медея» единственная, которая на протяжении многих лет занимает разве только самое крайнее место в интернациональном репертуаре. Несчастливая ее судьба сегодня становится более понятной, если помнить, что опера от Л. Бетховена и И. Брамса, признанная на равных с иными почитаемыми произведениями искусства, подверглась существенной переделке в работе 1855 года мюнхенского композитора Франца Ляхнера. Отличительным качеством стало то, что в этой переработке использовался итальянский текст Карло Цангарини, который часто отклонялся от французского оригинала. Ф. Ляхнер заменил произносимый текст оркестрово поддержанными речитативами; и хотя он этим вмешательством спасал оперу от ее уничтожения на сцене, но это на сегодня не стало основанием творческой практики» [9, с. 239] (здесь и далее пер. наш. - E. K.).

Из сказанного следует романтическая корректировка странного, по меркам XIX века, сочинения, явно трагического, в котором совершенно отсутствует дифференциация сил добра и зла - «демонизированы» в самовыражении все без исключения персонажи композиции (разве что минуя роли безмолвных жертв манипуляций Медеи - ее несчастных убиенных малолетних сыновей). Откровенная мифологичность сюжета, достойная больщой оперы, здесь сопряжена с разговорными диалогами, являющимися наследием реализма комического жанра. Напряженность событий, чудесно разрешающихся 
волшебным вознесением героини, что соответствует драматургическим принципам жанра «спасения», никак не выходит на нравственное разрешающее окончание, которое в данном сочинении отмечено лишь мучением и смертью виновных и невинных участников произошедших на сцене событий.

Вышеупомянутый Ф. Ляхнер «облагородил» оперное действо, отстранил речитативами от рывков разговорных прозаизмов к симфонически-ансамблевым симфониям и ариозным идеальностям выражения. Нечто подобное свершил Ж. Бизе относительно «Кармен», сделанной по литературному материалу П. Мериме, Э. Гиро, заменив «снижающие» разговорные диалоги Ж. Бизе на сочиненные им речитативы, тем самым «приподняв» в идеальности проявления жестокой «правды страстей» героев-люмпенов. Наверное, применительно к реализму места действия «Кармен» Бизе - Мериме это создавало соответствующий выразительный проверистский крен, который до сегодняшнего дня оказывается востребованным, несмотря на попытки воспроизведения оперы в оригинальной постановке.

Что касается «Медеи» Л. Керубини, то события мифологической Античности и реализм разговорных вставок составляют особого рода выразительный «надрыв», который не имеет отношения ни к «правде характера», ни к «правде отношений»: А. Хохловкина четко указывает, что композитор «не ставит перед собой задачи обрисовки психологического развития; его нет в музыке «Медеи» [5, с. 75]. Персонажи деморализованы исключительностью своего социального и культурно-мессианского статуса: для Язона важна только его функция героя - добытчика Золотого Руна, для Дирсеи и Креона - их место рядом с золотоносным героем, для Медеи - признание ее участия в героических действиях Язона. Сочувствие, милосердие, достойная восхваления кротость нрава - это все вне сферы событий «Медеи» и стиля самовыражения персонажей.

Волевое превосходство Медеи, удерживающей власть над событиями ценой безоглядной жестокости и отстраненной от каких бы то ни было бытовых привязанностей, - это уникальная сюжетная раскладка, к реалистическим устремлениям XIX столетия касательства не имеющая, что и обусловило несущественность музыкальной идеализации, сделанной Ф. Ляхнером относительно оперы Л. Керубини. Симптоматично то, что по инициативе М. Каллас совершенное возрождение на сцене «Медеи» Л. Керубини в первоначальном каче- 
стве свершилось почти столетие спустя после инициативы Ф. Ляхнера - в 1953 году, с восстановлением оригинальной французской версии разговорных вставок в симфонически-вокально насыщенную музыку [9, с. 239].

В опере «Медея» Л. Керубини присутствуют черты выражения, готовящие ампир «Весталки» и других сочинений Г. Спонтини. Ибо, хотя свои композиции последний и называл seria, сюжеты и музыкальное решение были далеки от превалирования христианского стоицизма в трактовке исторических и античных сюжетов и установок на гимнический блеск ариозного пения. Герои Г. Спонтини - волево и убежденно эгоцентрично действующие персонажи, в которых силовое проявление составляет основу эстетизации их образа. Таковы же персонажи «Медеи»: они попирают законы милосердия и сострадания - и Медея «пережимает» всех иных безоглядной жестокостью своего самоутверждения. В свете сказанного вызывает удивление музыковедческий вердикт А. Хохловкиной: «...трагический дуэт Медеи и Язона, сцена ее смерти делают оперу Л. Керубини подлинной героической драмой» [8, с. 192].

Действительно, смерть героини может внести нравственно-искупительную ноту за все ею и над нею свершенные злодеяния, создавая некоторый героический контекст, подобно тому как мученическая, самим героем вызванная на себя смерть Тараса Бульбы в знаменитой повести Н. Гоголя создает покаянный пафос за противоприродность сыноубийства, свершенного им. Но в «Медее» Л. Керубини этого нет. Действительно, великолепный в силовом единоборстве тандем преступников-героев в одном лице, Язона и Медеи, покоряет мрачным пафосом, где полнота мужской энергии Язона, обрушенная на женское существо отвергнутой жены-матери, создает нравственный перевес в сторону Медеи. Но заключительная сцена оперы (которую можно трактовать как символическую смерть героини - но событийно это никак не дано) являет совсем иное: «Когда во дворце раздается крик ужаса, вследствие того что Медеи ядовитый дар отнимает жизнь у невесты, умертвляет она своих собственных детей и швыряет их Язону в триумфующей ярости. Эвмениды охраняют ее уход, она исчезает в драконами запряженной карете, искры которой повергают королевский дворец в щебень и пыль» [9, с. 238].

Эта дьяволиада финала является избыточной для романтических демонизмов, поскольку безыдеальность содеянного героиней не оставляет никакого места нравственному принятию случившего- 
ся. Героическую трактовку образа оперы А. Хохловкина поддерживает ссылкой на авторитет Л. Бетховена: «Не случайно экземпляр «Медеи» Л. Керубини находился в личной библиотеке Л. Бетховена. Ноты испещрены пометками, показывающими углубленный интерес великого композитора к произведению, которое тщательно изучал» [8, с. 192]. Однако не секрет, что великий композитор с выраженным сочувствием на определенном этапе своей биографии отнесся к якобинской кровавой вакханалии, а именно пафосом всеразрушения государственных и семейных святынь проникнут революционный классицизм Л. Керубини.

Вышецитированный Р. А. Цондергельд следующим способом характеризовал данную оперу Л. Керубини: «Единственное в своем роде место занимающая опера в пределах своей эпохи представляла, возможно, наиболее важное запечатление эстетических канонов революционного искусства и его проявлений. В репрезентатирующем его полотне «Клятва Горация» Жана-Луи Давида заложены были окончательно форма и тематика. Суровость композиции, определившая мастерство всего последующего государственного искусства. Также в музыке Л. Керубини есть суровость и строгость с динамическим прорывом звучащих элементов, однако в «Медее» служащих не созиданию, но разрушению государственных структур» $[9$, с. 239].

Опера трехактна, такая композиция унаследована от «упрощенных» (по сравнению с пяти- и четырехактностью лирической трагедии) опер X. Глюка и практики жанра «спасения» (в том числе в знаменитом «Водовозе» 1800 г. самого Л. Керубини). Но указанная трехактность подана в той «крещендирующей драматургии» [7, с. 207] возрастания основной кульминации к финалу, которая в полноте обнаруживается в опере-ампир Г. Спонтини, откровенно «подменяющей» литургийное действо во славу выдвиженца революции Наполеона. Медея в опере Л. Керубини гораздо более аллегорична-собирательна по сравнению с Лицинием или другими quasi-историческими персонажами Г. Спонтини: очевидная мифологическая основа данного образа, ее надчеловеческая сущность обыгрывается сюжетно и сценически-постановочно.

В музыке рассматриваемой оперы Л. Керубини выделен прием, который не встречается в других его сочинениях - по крайне мере в той концентрации, которая обнаруживается в «Медее». Речь идет о самостоятельности ритмического фактора в донесении смысла 
происходящего, а также о приемах ритмических остинато, которые отличают драматургически базисные номера композиции. Что касается ритмического момента, то поражает, прежде всего, перенасыщенность музыки структурами пунктирных ритмов, которые, начиная с № 4 Арии Креона, категорически оттесняют славильнокантовый ритмический архетип, который показан в виде «вводного блока» в № 1-3, то есть до появления мысли о Медее (№ 4, Ария Креона) и выхода на сцену самой главной героини (№ 5, Ария в ритме мазурки, к 1797 г. четко ассоциированном с повстанческой Мазуркой Домбровского - об этом специально в работе И. Подобас [6, c. $73-75])$.

Последующий Дуэт Медеи и Язона дает первый этап концентрации пунктирных ритмов, впоследствии сопровождающих все номера всех трех актов сочинения. Но значимость указанного Дуэта заключается и в том, что в нем впервые обнаруживается опора на ритмическое остинато, которое с этого номера выдвигается на самозначимое положение в музыкальном звучании, создавая особого рода сосредоточение мысли на идее силового нажима, ассоциированного в эпоху революции с ритмами маршей, рожденных как жанр в указанные пламенные годы.

В опере явно выделено ведущее тональное соотношение $d$-moll $E s-d u r$, первая из тональностей показана в увертюре, а обе тональности от № 8 (Es-dur) и № $10(d$-moll) составляют некоторую постоянно действующую линию высотных предпочтений до конца композиции. Заметим, в данной опере значимость сольных арий-монологов не меньшая, чем ансамблевых сцен, в частности дуэтов-диалогов, которые можно по-вердиевски, по-вагнеровски определить как дуэты-поединки. Главное то, что драматургически этого рода сцены занимают узловое положение: дуэт Язона - Медеи завершает I действие (№ 6), аналогичный дуэт выделен как подготавливающий (№ 10) пугающее противостояние Медеи и Язона в окружении Креона, Дирсеи, хора жрецов и подданых № 11, завершающее II акт. Наконец, финал оперы № 14 решен как грандиозный диалог Медеи и Язона, из которых второй дан в могучем окружении приспешников и царедворцев. Любопытно, что в проклятьях, адресованных Медее, фигурирует в тексте обвинение - «Тиранка!», сделанное в актуально-политической терминологии 1790-х годов.

Инициатива в выборе значимых ритмо-формул в ансамблевых сценах принадлежит Медее, тогда как в сольных (Арии № 5 и № 13 в 
I и III действиях) концентрируется некоторый ритмообраз, создающий сюжетно оправданный сиюминутно значимый эмоциональный образ. В № 5 (F-dur, Larghetto) выше был отмечен мазурочный колорит со всеми ему присущими в конце XVIII столетия революционными ассоциациями смысла. В № 13 (Es-dur, Largo) развернуто драматическое противостояние контрастных крайних и средней частей составной репризной трехчастной формы, в которой каждый входящий в нее раздел отмечен самостоятельным ритмообразом. Так, в медленных крайних разделах в оркестровом пласте показана «фигура дрожания», символизирующая отчаянное сосредоточение Медеи на идее отмщения вопреки всему и вся.

Торжественность звучания мажорной тональности в медленном движении вводит тот забытый в постмадригальный период музыкальной истории Европы эффект первоначального значения мажорности как «твердого-жесткого», соотносимых, как в мадригалах Джезуальдо ди Веноза, Л. Маренцио и др., со словами «страдание», «смерть». В крайних разделах Арии выделена вторая тема (на текст «Вечный рок», B-dur), создавая просонатные отношения в экспозиционном показе тем первой части Арии. Средний раздел (Allegro moderato, $E s-d u r$ ) отмечен новым ритмическим элементом - в виде диалогического соотношения «обращенного» пунктира и кантовой фигуры, создающих столкновение императивных и молитвенных порывов, облекающих звучание термина «Милость» в тексте высказывания попранной и униженной царевны.

Начало среднего раздела в основной тональности привносит черты рондальности в просонатном изложении Арии. А в репризе сохраняются тональные показатели первого раздела, тем самым отодвигая сонатность в пользу контрастной рондальности. Собственно этого рода конструктивные признаки составляют отличительную черту композиции «Медеи»: «Крупные формы (сонатные, рондообразные) и масштабность симфонического развития ставят «Медею» на особое место в оперном творчестве эпохи» [5, с. 75]. Полнота же демонстрации этих «крупных форм» - чрезвычайно развернутые ансамблевые сцены. И особое место в них принадлежит финалу III акта. Тональный охват этого вокально-симфонического массива $B-d u r-D-d u r / d-m o l l$, как бы предвосхищает тональный план Девятой симфонии Л. Бетховена, составляющей в выразительном плане абсолютное продолжение поэзии Разрушения, которая запечатлена в финале «Медеи» Л. Керубини. 
Финал открывается звучанием $(d$-moll), в котором в басу рp выписан контур темы Распятия - в эпоху Французской революции поощрялись действа, замещавшие Богослужение «гражданскими литургиями» с текстами в честь Разума, Верховного существа и т. п. [5, c. 54-55], отмеченные музыкальной риторикой духовной музыки как таковой. Монолог Медеи вводит тональности ее Арии № 13 (B-dur, $E s$-dur), однако на новом уровне динамических преобразований в быстро сменяющихся темпах и, главное, в демонстрации предельных регистровых возможностей пения: опорность звуков $d^{1}$, $e s^{1}$ в связи с показом $d$-moll, рядом с которыми размещены выходы на $b^{2}$. Следующий этап противостояния Язона и Медеи отмечен в ее партии соотношением $c i s^{1}$ и $a^{2}-h^{2}$, что формирует демонический финал с заклятьем сил ада $(d-m o l l)$.

Приведенное описание призвано выделить явные протоэкспрессионисткие слагаемые образа Медеи в целом и соответствующие приемы, соотносимые совершенно с экспрессионистской вокализацией типа монологов Саломеи из одноименной оперы Р. Штрауса.

Как отмечалось выше, заслуга восстановления в оригинальном виде партии Медеи из одноименной оперы Л. Керубини принадлежит М. Каллас, кстати, бывшей также и знаменитой исполнительницей Юлии в «Весталке» Г. Спонтини, то есть сочинении, в значительной мере, и это отмечалось выше, подхватившем протоэкспрессионистские стимулы здесь рассматриваемой «демонически-революционной» композиции Л. Керубини. В литературе специально отмечается то, что у Марии Каллас в триумфальном исполнении роли Медеи в 1953 и последующих годах появились «последовательницы» в лице М. Оливеро (M. Olivero) и А. Фейрлл (E. Farell) [9, с. 239]. Пик интереса постановок «Медеи» - 1950-1960-е гг. $(1953,1962,1967)$ [9, c. 239], то есть период подъема музыки авангарда в европейской профессиональной традиции.

Из сказанного следует:

- опера «Медея» Л. Керубини образует исключительнгый случай в деятельности данного автора, соответствующий требованиям революционного классицизма в гораздо большей степени, чем иные авторские композиции данного рода;

- однако жанровое определение ее как «подлинной героической драмы» [8, с. 192], как показывает анализ, является пристрастной «бетховенизацией» видения произведения, в котором отсутствует тот идеальный позитив действий персонажей, вне которого понятие ге- 
роического бессмысленно, при всех трикстерских сопутствующих реального проявления героики;

- «крещендирующая» драматургия «Медеи» Л. Керубини, будучи исключительной в ряду сочинений указанного композитора, во многом определила драматургические открытия «оперы-ампир» Г. Спонтини, в совокупности пролонгируя «пропассионные» (см. у Е. Марковой [4, с. 126-134]) структуры-смысла произведений модерна-авангарда XX века;

- экспрессионистский тонус выражения обнаруживается в партии Медеи Л. Керубини в аналогию к регистровым «перебросам», объективно вырастающим из барочной «динамической пирамиды» [2], но реализующимся в контексте антиэстетических тенденций художественных достижений оперы XX века;

- партия Медеи и ее образ стали кульминацией признания исполнительского искусства М. Каллас в начале ее восхождения (1953) и в финале жизненной/творческой биографии (фильм П. Пазолини «Медея», поставленный с М. Каллас) [3];

- сосредоточение на образе Медеи определило проэкспрессионистиские составляющие стилевой исполнительской палитры М. Каллас, обнаружившиеся в их полноте в 1950-1960-е годы, то есть в момент исключительной влиятельности аванградного неоэкспрессионизма в европейской художественной традиции минувшего столетия.

\section{СПИСОК ЛИТЕРАТУРЫ}

1. Асафьев Б. Музыкальная форма как процесс / Б. Асафьев. - М. ; Л. : Музыка, 1971. - 379 c.

2. Круглова Е. Некоторые проблемы интерпретации вокальной музыки эпохи барокко [Электронный ресурс] / Е. Круглова. - Режим доступа : http://www.studzona.com/referats/view/38824; http://stmus.nm.ru/arc/104/414. htm; http://www.mmv.ru/sm/arta/09-05-2000 history.htm

3. Мария_Каллас [Электронный ресурс]. - Режим доступа : https:// ru.wikipedia.org/wiki/

4. Маркова Е. Интонационность музыкального искусства / Е. Маркова. - Киев: Музична Україна, 1990. - 182 с.

5. Музыка Французской революции XVIII века. Бетховен. - Москва : Музыка, 1967. - 443 с.

6. Подобас И. Мазурки Ф. Шопена в контексте варшавского бидермайера : дис. ... канд. искусствовед. : 17.00 .03 / И. Подобас. - Одесса, 2013. $173 \mathrm{c}$.

7. Холопова В. Музыка как вид искусства / В. Холопова. - Москва : Научно-творч. центр «Консерватория», 1994. - 260 с. 
8. Хохловкина А. Западноевропейская опера. Конец XVIII - первая половина XIX века : очерки / А. Хохловкина. - Москва : Гос. муз. издат., 1962. - $368 \mathrm{c}$.

9. Roessler A. Der große Opernführer. Werke, Komponisten, Interpreten, Opernhäuser / A. Roessler, S. Hohl. — Gütterslohn ; München : Durchgesehene Sonderausgabe für Bassermann Verlag, 2000. - $608 \mathrm{~S}$.

Мірзоян К. Образ Медеї в однойменній опері Л. Керубіні та їі виконавиі верciï. У статті розглянуто виразний потенціал стилю опери Л. Керубіні «Медея» та його відповідність вимогам революційного класицизму. Дається характеристика міфологічного підгрунтя головного образу опери - Медеї - на прикладі виконавського мистецтва М. Каллас. В ході дослідження доведено оригінальність теоретичної ідеї протоекспресіоністского сенсу образу Медеї та опери Л. Керубіні в цілому на противагу проромантичним установкам слухання «героїчного та високого».

Ключові слова: протоекспресіонізм, міф, образ, виконавське мистецтво, М. Каллас.

Mirzoyan E. Image of Medea in the opera of the same name and its L. Kerubini performing version. The article considers the expressive potential of Kerubini's opera style «Medea» and its correspondence to the requirements of revolutionary classicism. The characteristics of the mythological background of the main image of the opera - Medea - are given on the example of the performing arts M. Callas. The study proved the originality of the theoretical ideas protoekspressionists sense way of Medea and Kerubini's opera as a whole as opposed to proromantic settings hearing «heroic and exceptional».

Keywords: protoekspressionizm, myth, image, performing arts, M. Kallas.

Стаття надійщла до редакції 27.04.2016

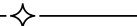

